\title{
mHealth: Technology for nursing practice, education, and research
}

\author{
Willa Doswell ${ }^{1}$, Betty Braxter ${ }^{1}$, Annette DeVito Dabbs ${ }^{2}$, Wendy Nilsen ${ }^{3}$, Mary Lou Klem ${ }^{4}$ \\ 1. Department of Health Promotion \& Development, School of Nursing, University of Pittsburgh, Pittsburgh, USA. \\ 2. Department of Acute \& Tertiary Care, School of Nursing, University of Pittsburgh, Pittsburgh, USA. 3. Office of \\ Behavioral and Social Sciences Research, Office of the Director, NIH. 4. Health Sciences Library System, School of Nursing, \\ University of Pittsburgh, Pittsburgh, USA
}

Correspondence: Willa Doswell. Address: Department of Health Promotion \& Development, University of Pittsburgh, School of Nursing, 3500 Victoria St. 440 Victoria Bldg. Pittsburgh, PA 15261, USA. Email: wdo100@pitt.edu.

Received: December 19, 2012

Accepted: February 15, $2013 \quad$ Online Published: April 2, 2013

DOI : $10.5430 /$ jnep.v3n10p99

URL: http://dx.doi.org/10.5430/jnep.v3n10p99

\begin{abstract}
Mobile health (mHealth) is a rapidly growing field providing the potential to enhance patient education, prevent disease, enhance diagnostics, improve treatment, lower health care costs and increase access to health care services, and advance evidence-based research. For the field of nursing the potential capabilities of mHealth are not only for patient care but for delivery of nursing education to our future practicing nurses, providing a means of communication between healthcare professionals located close and at greater geographic distances, and provides access to information and personal monitoring for geographically isolated clients. Although mHealth capabilities' value appears significant for training, and practice, there remains a significant need for research and evaluation of the devices that now appearing in the health care marketplace. The National Institute of Nursing Research's strategic plan includes supporting research to develop and test the flood of health apps to assist clients in the management of their health. The purposes of this paper are to: 1) discuss the importance of mHealth in nursing practice, education, and research, and 2) describe the mHealth initiatives underway at the University of Pittsburgh School of Nursing as exemplars to stimulate mHealth research and promote nursing role in providing health care to patients in this age of information technology.
\end{abstract}

\section{Key words}

mHealth, Mobile health, Mobile technology, Nursing

\section{Introduction}

Mobile health (mHealth) is a rapidly growing field. These technologies provide the potential to advance research, prevent disease, enhance diagnostics, improve treatment, enhance education, reduce disparities, increase access to health services and lower healthcare costs in ways previously unimaginable. In this paper mobile technology is defined as wireless devices and sensors (including mobile phones) that are intended to be worn, carried, or accessed by the person during normal daily activities. mHealth is the application of these technologies either by consumers or health care professionals. The purpose of this article is to describe the current usefulness and opportunities for the implementation of mobile health technologies within nursing practice, education, and research. 
For the field of nursing, the potential capabilities of mHealth address many of the most pressing concerns. mHealth, like nursing, not only addresses illness, but also methods to enhance health and support disease prevention. Similarly it is also a methodology that not only supports service provision in the field, but also enhances education of future professionals. For instance, the strategic plan of the National Institute of Nursing Research's (NINR) at the National Institutes of Health (NIH) predicts that nursing will be at the forefront of using innovative health technologies to enhance health. NINR encourages nursing researchers by extending calls for research for "innovative methods that optimize patient outcomes and, at the same time, contain costs.” There is also an acknowledgment that nursing will thrive in the multidisciplinary environment that is needed to successfully implement mHealth. The NINR strategic plan notes "Interdisciplinary partnerships are needed to design creative interventions that use existing and emerging technologies and consider the multiple factors that impact behavioral change. Research that tests these strategies will provide the scientific evidence for future health promotion and disease prevention interventions that can be applied in home, community, workplace, and clinical settings."

Although this example focuses on research, the American Nurses Association (ANA) also highlights the value of technology for their field, including their recent "mobilization” challenge (http://www.nursingworld.org/MainMenuCategories/ThePracticeofProfessionalNursing/Health-IT/Mobilizing-Data-for-Pressure-Ulcer-Prevention-Challenge.html).

Thus, the real-time, continuous biological, behavioral and environmental data collected by mHealth technologies should improve our understanding of the etiology of health and disease, particularly when integrated with data from areas such as genomics, biomarkers, and electronic medical records and leveraged with behavioral change interventions. Enabled by wireless technology, a major opportunity also arises from the potential of mobile health technologies to continuously monitor chronic medical conditions that are afflicting people around the world, as well as to promote health behaviors and implement disease self-management plans that capitalize on this expanded information. Chronic disease conditions have been recognized in the developed world as a major source of morbidity and mortality. Similarly, in the low- and middle-income countries, chronic disease is increasingly being cited as an emerging problem and a major component of disease burden. A prospective study by Andersen and Chu ${ }^{[1]}$ notes that cardiovascular disease accounts for nearly $30 \%$ of all. Although problems like chronic health conditions are key targets of emerging mHealth research, the hypothesis that better monitoring with mobile technology will lead to better management, better outcomes and reduced disease burden has yet to be adequately tested. These are prime areas for nursing researchers to move this field forward.

The need for rigorous research that examines the potential, as well as the challenges, of harnessing mobile technologies to improve health outcomes is critical. Mobile technologies have developed at an exponential pace in recent years; however, the integration and translation of these cutting-edge technologies into rigorously evaluated nursing research, education and practice tools have lagged behind. In fact, development of mHealth technologies is currently progressing at a much faster pace than the science to evaluate their validity and efficacy, introducing the risk that that ineffective or even potentially harmful applications will be implemented. These rapid technological advances in mHealth generate both opportunities and challenges that offer many opportunities for those in nursing research, education and practice.

Although mHealth is a nascent promising field, it has not gone unnoticed by the NIH and other government bodies (e.g., the Office of the National Coordinator for Health Information Technology). NIH has been especially active in areas such as research training and methodology, as well as directly funding research in mHealth. Clearly, nurse educators, practitioners, and researchers need to be able to examine the effectiveness, as well as the appropriateness, acceptability, and adherence of patients and providers to high-tech health solutions and collaborate with the myriad of disciplines that contribute to such efforts. This article proposes to discuss the important role of mHealth in practice, education and research as nurses continue their important role of providing health care to patients in this age of information technology.

\section{1 mHealth in nursing practice}

A survey of recent literature on the use of mHealth in nursing practice revealed 13 mHealth studies conducted in hospitals or other clinical environments. These studies ranged from examining the impact of mHealth technology on communication, patient satisfaction with nursing services, ro symptom management and evidence-based practice. 
O'Connor, Friedrich, Scales, and Adhikari ${ }^{[2]}$ found that use of wireless email devices had a positive impact on communication among physicians and nurses working in an intensive care unit, while Straka ${ }^{[3]}$ similarly found signifycantly improved satisfaction with nursing services by encouraging patients and families to use a cell phone assigned to a unit nurse, rather than the existing call bell system. While these initial results are encouraging, Wu and colleagues ${ }^{[4,5]}$ present a more complex picture of the potential impact of mHealth devices. Senior residents on general internal medicine inpatient units were provided smartphones to send e-mails to nurses and other healthcare professionals for non-urgent updates or questions, using direct phone calls only for emergencies or urgent questions ${ }^{[4]}$. Initial results indicated that residents felt the smartphone system made it easier to communicate with health care professionals but were concerned about disruptions caused by phone calls occurring during their conversations with patients ${ }^{[4]}$. Nurses reported apparent decreases in the time required to contact residents, but did not see improvements in any other aspects of communication. In a subsequent qualitative analysis ${ }^{[5]}$, medical residents reported appreciation of the efficiency of the phone system, but felt overwhelmed by emails and ignored low importance emails. Nurses appreciated the efficiency of the smartphone system, but believed it led to a worsening in interpersonal relationships caused by lack of face-to-face interactions.

Several studies have examined the impact of mobile devices on nurses' access to patient or clinical data. Weaver and colleagues ${ }^{[6]}$ tested the feasibility of patient use of mobile phones to report chemotherapy side effects. Nurses monitored the reports and received alerts via pager if patient ratings of symptoms exceeded pre-established thresholds. Both nurses and patients reported satisfaction with the mobile reporting system, patients noted that they felt closely monitored while not unnecessarily bothering the nurses, and nurses noted that they felt better able to manage the amount of patient symptom information generated by the system.

Andersen, Lindgaard, Prgomet, Creswick and Westbrook ${ }^{[7]}$ studied the usability of various types of mobile technology (tablet computers versus computers on wheels versus stationary PC), for routine patient care, hypothesizing that clinician's roles and tasks (which drive clinical work flow) would influence healthcare providers' device preferences. The computer on wheels (COW) was the preferred device for both nurses and physicians, although its size made it a challenge to use while in a patient room. Interesting, this preference seemed driven in large part by the design of the COW trolley or cart it provided both table and storage space for items other than the computer. Nurses reported that the tablet PC was inconvenient to carry around or set down when in a patient room, and also expressed concerns about lack of training in use of these portable devices.

In addition to patient or clinical data, mobile devices have also been studied as a means of providing evidence-based information to clinical nurses. Doran and colleagues ${ }^{[8,9]}$ evaluated a large-scale program providing registered nurses with access to treatment guidelines, research summaries, and drug/medical reference information via PDAs or tablet PCs. Of the nurses enrolled in the program, 29\% never used either device given to them. Those who used the device reported that practice guidelines available were the information resources easiest to access on the devices. Improvement in quality of care provided and job satisfaction was reported by nurses using either type of device, but greater change was observed in PDA users. This appeared to be a function of design - the tablet was bulky, hard to carry, and slow to load. Additionally a study by McBride ${ }^{[10]}$ revealed that as advantageous as mHealth technology may be to patient care, there is the potential problem of it causing distraction to the nurses implementing it with time needed to learn the technology and implement it on busy and understaffed units.

\section{2 mHealth in nursing education}

The American Association of Colleges of Nursing (AACN) ${ }^{[11]}$ in The Essentials of Baccalaureate Education indicate nursing programs should prepare graduates to use technology to promote effective communication in diverse health care settings, and to improve patient outcomes. The mandate suggests that schools of nursing must therefore prepare students to effectively practice in highly technologically sophisticated health care environments. In response to the AACN's directive, schools of nursing have initiated an evaluation of their current curricula to ensure that BSN graduates meet the technological demands they will face when practicing nurses in the field. Below is an overview on how nursing schools are using mobile health technologies to assist faculty to prepare the next generation of nurses to meet the mobile technological demands. 
Students currently entering nursing programs are frequently described as the Millennial generation (i.e., individuals born between 1981 and 2000). The Millennial generation was raised with the Internet and technology has always been available. Today's students are often more comfortable with the various mobile technologies than their respective nursing faculty. A national study describing undergraduate students use of information technology by the EDUCAUSE Center in 2011 found students own varied technological devices that include: laptops-87\%, smartphones-55\%, netbooks - 11\%, and iPads-8\% ${ }^{[12]}$. Students who owned a netbook, iPad or another tablet type often used the device for academic purposes. The national survey also found that approximately $57 \%$ of all students used e-textbooks or e-books that were downloadable to their devices. Furthermore, the survey reported the most frequent communicative software applications used by students for academic purposes ranged from email as number one, followed by text messaging, Facebook, and instant messaging ${ }^{[12]}$. This generation of students is used to being connected to the outside world 24 hours a day 7 days per week. Students desire to be connected to the faculty, classroom, educational materials, and clinical arena, at all times with the click of a button.

\section{PDAs (Personal Digital Assistants)}

PDAs allow nursing students immediate access to different resources (e.g., medication references) as handheld devices. Additionally, students are able to track clinical hours, and jot down notes using PDAs A body of work ${ }^{[13-15]}$ suggests the use of PDAs has become a focus of inquiry within nursing education. A survey conducted by RNs are Mobilizing (2003) conducted by Forrester Research ${ }^{[16]}$ reported PDA usage was important in nursing education among $60 \%$ of respondents. A study with 150 nursing schools found that $26.7 \%$ of the schools required PDAs ${ }^{[17]}$. Another recent study of sophomore students found that approximately 95\% of the surveyed students reported they used the PDA one to five times per day to look up information in class or in clinical settings, and 73\% of students reported that the PDA with clinical support tools increased their clinical and classroom productivity. Faculty also viewed the PDA as beneficial. The device was a tool that faculty used to engage students given learning activities (e.g., questions) were linked with different media (i.e., still images as well as video and audio streams). Other studies have also found that PDAs: 1) contributed to students' learning in the classroom and clinical setting, 2) allowed for quick retrieval of information, and 3) were viewed by students as a valid educational tool ${ }^{[18-21]}$. Problems associated with PDA usage include: 1) transitioning from PDAs to newer forms of mobile technology (e.g., Ipad), and 2) limited intake and output capability.

\section{E-textbooks}

An electronic textbook) (e-textbook) is typically described as an instructional book in an electronic format. A survey by the National Association of College Stores (NACS) ${ }^{[22]}$ found 13\% of the students surveyed had purchased an e-textbook within the past 3 months due to the requirement of their professors. One year earlier another study by On Campus Research ${ }^{[23]}$, a division of the NACS, reported that students were predominantly reading e-books on a computer (77\%). About $19 \%$ of students endorsed use of an e-book on a smartphone (e.g., iPhone, Blackberry, or Android) with only $4 \%$ of students reporting use of an e-book on a tablet computer (e.g., iPad). Another study conducted by the Student Public Interest Groups (SPIG) ${ }^{[24]}$ found $40 \%$ of students with some familiarity with e-readers reported that they were "likely" or "very likely" to switch from printed textbooks to electronic (www.studentpirgs.org). Although the SPIG study also found print was still preferred, students liked both print and electronic books. The advantages of using e-books are typically identified as flexibility, accessibility, and capability to link to videos and other software. An article in the Chronicle of Higher Education by Young ${ }^{[25]}$ described initial problems using e-books included the absence of page numbers with some handheld devices. and inability of students to resale the downloaded textbooks. Additional problems linked to e-textbooks include decreased comfort compared to regular textbook ${ }^{[26]}$, and cost issues given students are unable to resale e-books.

Scarce literature is available on the use of e-textbooks in nursing education. One study by Williams and Dittmer ${ }^{[27]}$ was retrieved. The study focused on the use of electronic books in handheld devices within nursing. Using a quasiexperimental design, sixty one students were divided into five control and five experimental groups. Participants in the experimental groups received handheld devices loaded with three e-books that respectively targeted diseases, lab values and medications. The handheld devices were used during preclinical preparation and on the clinical unit. Both groups completed a pretest and a posttest. At the posttest, students were queried on their perceptions about the e-books in addition 
to questions related to the handheld device, time, and clinical preparation facile. The findings suggest a preference of e-books ( $p=0.000$ ) among the experimental groups from pre to post. A majority of the overall sample indicated that the loaded handheld devices allowed students to more efficiently and effectively prepare for clinical.

\section{SmartPhones}

With the introduction of the Blackberry device in 2002, the era of the smartphone began. A smartphone is an expanded version of the cellular telephone. The smartphone has built-in applications and Internet access (www.pcmag. com). Additionally, smartphones provide for email and text messaging, Web browsing, and the ability to use a still and video camera, and MP3 player, and finally video playback calling. Smartphones have also been described as newer technologies that incorporate features of PDAs. Smartphone applications "apps” are essential to utilization. With apps, students are able to look up patient medications, perform calculations, and calculate the expected date of confinement. Applications may be freely available. However smartphones require voice, text and data plans to support internet access and wireless and/or cellualar communication, thus cost is an issue. The capabilities and functions of the smartphone may be adapted for use in nursing education in both the classroom and clinical arena. Phillippi and Wyatt ${ }^{[28]}$ reported that instructors may utilize the phone to text or send messages out to students as reminders related to didactic or clinical activities. With the video player feature, students may watch instructional videos.

Additionally, smartphones may be utilized for debriefing purposes. A study by Healthcare Human Factors ${ }^{\text {[29] }}$ found practicing nurses preferred light weight, and portable compact devices that have a protective cover that may be easily washed with a disinfectant (http://humanfactors.ca/projects/smartphonesfornurses/). Mosa, Yoo and Sheets ${ }^{\text {[30] }}$ in a systematic review of smartphone utilization in healthcare evaluated 55 articles with applications documented. The applications primarily focused on disease diagnosis. Eleven applications designed for medical or nursing students had an education focus. Another study with senior nursing students assessed the frequency of smartphone use by the students during a 10-week clinical rotation, and explored the students' perceptions about smartphone use during the rotation ${ }^{\text {[31] }}$. The frequency of use ranged from 2 to 55. A limitation of the study was different methods were used by the students to document usage. During a focus group with study participants, three themes emerged: 1) resource- the resource applications on the phone were linked to making care easier and faster to deliver, 2) confidence- increased confidence in for example giving the correct medication, and 3) safety. Barriers were also identified during the focus group: expense, limited battery life of the phone, and may not be best learning strategy for all.

In summary, a review of the literature on the use of mHealth technologies in nursing education has focused on an expanding body work on the use of PDAs, and the early work on use of e-textbooks, and Ipads. The use of mHealth technologies is promising given the findings from descriptive studies suggest the use of the technologies is linked to an increase in clinical and class preparation. The next steps should target an evaluation of the impact of mHealth technologies on clinical and class preparation using both quasi-experimental and experimental designs. Qualitative studies will also be helpful as we move forward and will continue to provide insight on students and faculty perceptions on use of the technologies at the point of care (i.e., clinical units). Nursing educators will also need to look at patients views on nursing students use of technologies during the clinical rotation. Another exciting area of inquiry moves from looking at students use of the technologies to that of faculty use within the didactic classroom and the hospital setting.

\subsection{Nursing research to develop and evaluate mHealth}

Novel systems such as mobile technologies are changing the ways in which nurses intervene, access health information, and communicate with patients and other care providers, thus enhancing prevention, diagnosis, and treatment of illness and health promotion. Consumer-centric nursing interventions are having an increasingly important role in empowering individuals and families to actively partner in monitoring and managing their own health, thereby reducing illness burden and promoting independence and quality of life ${ }^{[32-34]}$. The rapid advance of technologies, combined with the burgeoning number of elders and persons living in the community with complex illnesses and disabilities, underscores the need to for 
nurses to examine the vital role of technology in promoting better health outcomes within an interdisciplinary context ${ }^{[35]}$. To ensure the appropriateness, acceptability, and adherence of patients and providers to high-tech health solutions, nurses collaborate with a myriad of disciplines that contribute to such efforts.

NIH is the major source of health research funding in the United States and its Director, Dr. Frances Collins ${ }^{[36]}$ predicted one of the greatest impacts of mHealth technology would be the explosion of materials available by smartphone to treat hundreds of diseases affecting the world. Although mHealth technology has been in use for several years, there is still a modest amount of published research using this technology in the nursing research literature. A few examples are provided here. Bell et al. ${ }^{[37]}$, conducting a study to examine whether mobile phone delivered one-way video messages about diabetes improved self-monitoring of blood glucose levels. This technology was successful for study participants who engaged in use of these video messages at least 10 times per month. Using qualitative interviews and mindfulness cognitive therapy, Jelin, Granum \& Eide ${ }^{[38]}$ examine the use of text-based communication between health care providers and their patients with chronic pain. A web-based home intervention followed in-house multidimensional rehab. Study participants reported that though they found the messages motivating and supportive, they expressed some ambivalence in using this format, and that messages were also challenging, as was having this detached (yet trusting) experience with their therapist.

Resnick et al. ${ }^{[39]}$ found the use of telehealth kiosks to monitor blood pressure was eagerly embraced by senior citizens at community-based senior citizen centers. Study participants reported being very comfortable with the technology: $81 \%$ reported the technology was easy to use, and $89 \%$ reported they would recommend its use to their friends. Wu et al. ${ }^{[5]}$ conducted a study to examine the use of smartphones to enhance communication between health care providers. The study examined frequency of smartphone calls, e-mail messages, and data provided through clinican interviews and ethnographic observations of clinical communication interactions. Although findings showed a perceived improvement in efficiency of communication through smartphones (over pagers) there was some ambivalence that smartphones created interruptions and discordance between what doctors and nurses perceived as urgent and needing delivery by smartphone. Nurses also perceived a worsening in interprofessional relationships due to overreliance on the use of text messaging devices and not enough on face-to-face contact. Dowdell, Burgess and Flores ${ }^{[40]}$ present research on the use of social networks by adolescents, young adults, and sex offenders and found their paths can cross in significant and potentially dangerous ways, that health care providers need to consider when conveying health interventions and clinical information via these methods.

Studies by Dunphy et al ${ }^{[41]}$ and Kidd ${ }^{[42]}$ also highlight the use of mHealth technology in providing hands-free communication for nursing while highlighting the challenges produced as well. Finally, a study by Lyles, Harris, Flowers and Tufano ${ }^{[43]}$ describe their pilot study with patients with type 2 diabetes who received electronic medical record information, wireless glucose reading uploads and e-mail between themselves and their health care providers. Study participants liked the glucose upload information activity but felt frustrated using cell phones and the game system used to connect to the web. In summary these studies provide evidence that there are advantages for improved health care and patient monitoring offered thru mHealth technology, but there is also an increase in patient and health care provider communication with the use of mHealth and the technological glitches that can occur. Lastly from a theoretical and measurement perspective, DeVito Dabbs et al ${ }^{[44]}$ proposed a model for intervention fidelity for technology-based behavioral interventions, which was found to be feasible and effective in assessing interventionists' delivery and participants' acceptance of the technology-based behavioral intervention. This framework may be useful in guiding the development of fidelity monitoring tools for technology-based behavioral interventions.

A School Exelmplar of mHealth Initiatives to stimulate mHealth Research. The faculty of the University of Pittsburgh School of Nursing demonstrates involvement and leadership in the area of technology and nursing as evidenced by the following three initiatives and selected mHealth projects described below. First, a growing number of faculty have well-funded, technology-based programs of research, the majority of which involve mobile health interventions. Few 
schools of nursing have the cadre of faculty involved in designing and testing technology-based nursing interventions that exist at the University of Pittsburgh School of Nursing. The faculty is designing and evaluating technological solutions to address and resolve health problems and prepare the nurse educators of tomorrow. Faculty members employ the gamut of technological platforms and applications including mobile devices, robotics, augmentative communication devices, biofeedback, and the Internet to improve adherence to the medical regimen, prevent illness, injury, or disability, and promote self-management and communication with health providers. The faculty members have a long history of serving as the principal investigators and leading interdisciplinary teams from other Schools within the University (Medicine, Health and Rehabilitation Sciences, Bioinformatics, and Bioengineering), Centers within the University and the University of Pittsburgh Medical Center Health System, and external to the University most notably through the Quality of Life Technology Center, an Engineering Research Center (NSF 0540865-2006-2016) led jointly by the University of Pittsburgh and Carnegie Mellon University, for which several School of Nursing faculty play a prominent role. Thus, this School has provided a template of faculty who possess the experience in research and mentoring needed to prepare nurse scientists to design and evaluate mHealth interventions. This template can be replicated to other schools or join with other Schools of Nursing throughout the country thus providing a potential network of mHealth research.

Second, the University of Pittsburgh School of Nursing received a federally funded T32 titled, Technology: Research in Chronic and Critical Illness (T32 2NR008857 PI, Judith Erlen) in 2005. The overarching goal of this T32, Technology: Research in Chronic and Critical Illness, is to provide rigorous research training and interdisciplinary aculturalization to build the nursing science aimed at promoting health, managing illness, reducing disability, and enhancing quality of life through the aid of technology. The specific aims of the program are to provide: 1) the theoretical and conceptual foundation to support the development of a program of research that examines ways that technological applications may enable the prevention, detection, or resolution of health problems; 2) the methodological skills to support of the development of an academic research career; 3) an environment that promotes, supports, and sustains scholarly inquiry within an interdisciplinary context; and 4) opportunities to identify, develop, evaluate, and translate novel technological applications to real-world nursing practice settings. Unquestionably, this program will enable nurse trainees to be well-positioned to conduct innovative, state-of-the-art research in this growing field.

Third, in the fall of 2011, the School of Nursing established a Technology Special Interest Group (TECH SIG) comprised of faculty and trainees who share an interest in the design and testing of technology-based interventions to support health behaviors. The goals of the bi-monthly SIG are to: 1) establish our place as leaders in the field of health technology by increasing visibility and dissemination of our activities; and 2) provide a forum for peer mentoring and support for School of Nursing faculty and trainees who are interested in health technology. The group began by sharing experiences regarding the challenges that commonly arise in the design and testing of technology-based interventions. The majority of the research projects use mobile health technologies, so we discussed how to best select phones, data plans, promote connectivity and security. Through this forum we also discovered that most of SIG members used behavioral or biobehavioral models to guide their research without explicitly including depictions of how and why technology was important as the intervention platform. The SIG worked to gain a better understanding of how to integrate and represent theories related to technology development, acceptance and adoption with the theories of behavioral change that underpinned the interventions being designed and tested. Based on these discussion, the need for a universal technology model for a wide-range of theory-based, technology-mediated bio/behavioral interventions is being developed.

Three funded investigators are part of this SIG. Using ecological momentary assessment (EMA) surveys delivered via smartphone, Dr. Burke is conducting a study of real time data collection from a smartphone to retrieve weight, daily diaries, actigraph and accelerometer to study the triggers of relapse during and following intentional weight loss ${ }^{\text {[45] }}$. EMA assesses individuals' current experiences, behaviors, and moods as they occur in real time and in their own environment ${ }^{[46]}$. Additional measures include the use of a wireless scale that transmits participants' weight in real time, as well as actigraphy to assess sleep and an accelerometer to measure physical activity. (HL\#1073770). 
Dr. Schlenk is conducting the STAR (Staying Active with Arthritis, R01 NR010904) study to investigate how an individually delivered home-based intervention influences lower extremity exercise, fitness walking, functional status, blood pressure, quadriceps strength, pain, and health-related quality of life in adults age 50 years or older with osteoarthritis of the knee and hypertension. The intervention uses an e-diary to capture data on physical activity. Dr. DeVito Dabbs is evaluating an mHealth intervention, Pocket PATH ${ }^{\circledR}$ Personal Assistant for Tracking Health (DeVito Dabbs, Meyers et al., 2009) ${ }^{[33]}$. In that study lung transplant patients are given smartphones with custom programs to promote their active involvement in care and assist them to perform a variety of self-care behaviors, including keeping track of various health measurements, following their complicated health regimens, and reporting changes in their condition to their clinical providers in a timely manner. An RCT examining its efficacy is nearly completion (R01NR010711). Early results indicate that Pocket PATH is superior to standard care in promoting self-care behaviors and clinical outcomes ${ }^{[4]]}$.

\subsection{NI H mHealth research training}

Although many government agencies and groups, such as the ANA, have an interest in mHealth in research, training and practice, the NIH has been very active in this area, especially in focusing on the role of nurse in this developing field. As noted throughout this paper, developing optimal mHealth technologies requires building research, professional and educational capacity. In the area of research, The NIH, in collaboration with the technology industry, has led a series of mHealth trainings to address the capacity of the scientific field to accommodate the demands of these new technologies [48]; see also http://obssr.od.nih.gov/training_and_education/mhealth/index.aspx). mHealth research ideally should draw from clinical expertise, behavioral and social sciences research (which will provide the science to guide intervention development and behavior change), user interface design, sensing technology, computer science and statistical inference to improve health outcomes. Reviews of much of the developing mHealth technology suggest some of the work being done arises from the technology industry and communication/marketing fields with a focus on the creation of high end products with little reference to behavior theory or to potential application in healthcare settings ${ }^{[49]}$.

These training institutes are a cross-training event for investigators with interest in mHealth. Core faculty included experts from behavioral and social sciences, medicine and nursing, engineering and computer science, as well as program staff from NSF, the Food and Drug Administration and NIH. The highly completive application process is designed to yield 28 participants with expertise in clinical research (medical or nursing specialties), behavioral and social sciences, computer sciences and engineering. The training curriculum covered the current state of the science in mobile technology and engineering, behavior change theory and clinical applications, and highlighted the intersection among these areas for research related to health. The participants' immersive experience in the basic and applied science of mHealth allowed them to improve their own design and mHealth research, while building research capacity as a whole in this important new field to improve health. These trainings are useful for nurse researchers, until the capacity of the field allows these opportunities to be developed by faculty at the universities.

\section{Methodology}

Because quality science requires solid scientific methodology, the NIH has been very active in the area of mHealth research methodology. One of the major efforts in this area has been the 2011 mHealth Evidence meeting (http://obssr.od.nih.gov/scientific_areas/methodology/mhealth/mhealth-workshop.aspx) sponsored by the Pioneer Portfolio the Robert Wood Johnson Foundation; the McKesson Foundation; the NIH; and the National Science Foundation. On August 16, 2011, researchers from the domestic and international community, policymakers, health professionals, technologists, and representatives from regulatory and funding agencies gathered for to discuss and identify more effective methods to generate evidence of efficacy and effectiveness for the unique emerging science of mHealth. The meeting targeted three areas that affect research in mHealth: study design methodology, data aggregation and 
statistical strategies, and infrastructure innovation. The meeting was video-taped to be a resource for the community and an in-depth paper covering the research content of the meeting is being developed by the participants.

\section{Conclusion}

Novel systems such as mobile technologies are changing the ways in which nurses intervene, access health information, and communicate with patients and other care providers, thus enhancing prevention, diagnosis, and treatment of illness and health promotion. Consumer-centric nursing interventions are having an increasingly important role in empowering individuals and families to actively partner in monitoring and managing their own health, thereby reducing illness burden and promoting independence and quality of life ${ }^{[32-34]}$. The rapid advance of technologies, combined with the burgeoning number of elders and persons living in the community with complex illnesses and disabilities, underscores the need to for nurses to examine the vital role of technology in promoting better health outcomes within an interdisciplinary context.

The rapid introduction of mHealth into nursing practice also dictates that nurse educators train our current and future nursing students in the methods of mHealth so they are prepared to deliver these new strategies of care. The rapid rise of mHealth technology also provides an opportunity and mandate that nurse researchers engage in evidence-based randomized controlled trials that will affirm the effectiveness of these strategies in providing optimum health care ${ }^{[50]}$. This paper has provided some highlights of mHealth activities currently happening in nursing locally, in the published literature, and at NIH, where mHealth is providing a national focus through its efforts in training, methodology, and grant funding.

Note: The opinions expressed herein are the responsibility of the authors and in no way should be seen as an official recommendation, interpretation, or policy of the National Institutes of Health or the U.S. Government.

\section{Funding}

mHealth research is funded throughout most of the NIH Institutes and Centers. Quality mHealth research may not be the target of a specific funding announcement, but it is always welcome through the NIH Parent Announcement mechanisms (Investigator-Initiated Awards: http://grants.nih.gov/grants/guide/parent_announcements.htm). This includes traditional grant mechanisms such as the R01 and R03, but also training mechanisms ( $\mathrm{K}$ awards) and small business innovation awards (SBIR and STTR/R33 and R44). For specific announcements, NINR has led in this area with a program announcement "mHealth Tools to Promote Effective Patient-Provider Communication, Adherence to Treatment and Self Management of Chronic Diseases In Underserved Populations” (PA-11-330, PA-11-331 and PA-11-332: http://grants.nih. gov/grants/guide/pa-files/PA-11-330.html). These announcements target innovative use of mobile technologies by nursing researchers to a range of issues common in chronic disease. This announcement also acknowledges the value that mHealth can provide in supporting health care in underserved populations. This is likely one of many potential announcements targeting the growing field of mHealth from NINR and the rest of NIH.

\section{References}

[1] Anderson GF, Chu E. Expanding priorities--confronting chronic disease in countries with low income. New England Journal of Medicine. 2007; 356(3): 209-211. http://dx.doi.org/10.1056/NEJMp068182

[2] O'Connor C, Friedrich JO, Scales DC, Adhikari NK. The use of wireless e-mail to improve healthcare team communication. Journal of the American Medical Informatics Association. 2009; 16(5): 705-713. http://dx.doi.org/10.1197/jamia.M2299

[3] Straka KL. Wireless telephone systems and the impact on patient satisfaction scoring: a pilot study. Journal of Pediatric Nursing. 2010; 25(1): 33-34. http://dx.doi.org/10.1016/j.pedn.2008.06.002

[4] Wu RC, Morra D, Quan S, Lai S, Zanjani S, Abrams H, Rossos PG. The use of smartphones for clinical communication on internal medicine wards. Journal of Hospital Medicine. (2010); 5(9): 553-559. http://dx.doi.org/10.1002/jhm.775 
[5] Wu R, Rossos P, Quan S, Reeves S, Lo V, Wong B, Cheung M, Morra D. An evaluation of the use of smartphones to communicate between clinicians: a mixed-methods study. Journal of Medical Internet Research. 2011; 13(3): e59. http://dx.doi.org/10.2196/jmir.1655

[6] Weaver A, Young AM, Rowntree J, Townsend N, Pearson S, Smith J, Gibson O, Cobern W, Larsen M, Tarassenko L. Application of mobile phone technology for managing chemotherapy-associated side-effects. Annals of Oncology. 2007; 18(11): $1887-1892$. http://dx.doi.org/10.1093/annonc/mdm354

[7] Andersen P, Lindgaard AM, Prgomet M, Creswick N, Westbrook J I. Mobile and fixed computer use by doctors and nurses on hospital wards: multi-method study on the relationships between clinician role, clinical task, and device choice. Journal of Medical Internet Research. 2009; 11(3): e32. http://dx.doi.org/10.2196/jmir.1221

[8] Doran D M, Haynes R B, Kushniruk A, Straus S, Grimshaw J, Hall LM, Dubrowski A, Di Pietro T, Newman K, Almost J, Nguyen H, Carryer J, Jedras D. Supporting evidence-based practice for nurses through information technologies. Worldviews on EvidenceBased Nursing. 2010; 7(1): 4-15. http://dx.doi.org/10.1111/j.1741-6787.2009.00179.x

[9] Doran D. The emerging role of PDAs in information use and clinical decision making. Evidence-Based Nursing. 2009; 12(2): 35-38. http://dx.doi.org/10.1136/ebn.12.2.35

[10] McBride DL. The distracted nurse. Journal of Pediatric Nursing. 2012; 27(3); 275-276. http://dx.doi.org/10.1016/j.pedn.2012.02.002

[11] American Association of Colleges of Nursing. The essentials of baccalaureate education for professional nursing practice. Washington, DC: Author, 2008.

[12] Dahlstrom E, de Boor T, Grunwald P, Vockley M. ECAR national study of undergraduate students and information technology [Internet]. 2011. Available from: http://net.educause.edu/ir/library/pdf/ERS1103/ERS1103W.pdf

[13] Beard KV, Greenfield S, Morote ES, Walter R. Mobile technology: lessons learned along the way. Nurse Educator. 2011; 36(3): 103-106. http://dx.doi.org/10.1097/NNE.0b013e3182161016

[14] Zurmehly J. Personal digital assistants (PDAs): review and evaluation. Nursing Education Perspectives. 2010; 31(3): $179-182$. PMid:20635623

[15] Scollin P, Callahan J, Mehta A, Garcia E. The PDA as a reference tool: libraries' role in enhancing nursing education. Computers, Informatics, Nursing: CIN. 2006; 24(4): 208-213. http://dx.doi.org/10.1097/00024665-200607000-00007

[16] PDA CORTEX. RNs are mobilizing [Internet]. 2003. Available from: http://www.pdacortex.com/RNs_are_Mobilizing.htm

[17] Smith CM, Pattillo RE. PDAs in the nursing curriculum: providing data for internal funding. Nurse Educator. 2006; 31(3): 101-102. http://dx.doi.org/10.1097/00006223-200605000-00004

[18] Cibulka N J, Crane-Wider L. Introducing personal digital assistants to enhance nursing education in undergraduate and graduate nursing programs. Journal of Nursing Education. 2011; 50(2): 115-118. http://dx.doi.org/10.3928/01484834-20101230-07

[19] George LE, Davidson LJ, Serapiglia CP, Barla S, Thotakura A. Technology in nursing education: a study of PDA use by students. Journal of Professional Nursing. 2010; 26(6): 371-376. http://dx.doi.org/10.1016/j.profnurs.2010.08.001

[20] Farrell MJ, Rose L. Use of mobile handheld computers in clinical nursing education. Journal of Nursing Education. 2008; 47(1): 13-19. http://dx.doi.org/10.3928/01484834-20080101-03

[21] Miller J, Shaw-Kokot JR, Arnold MS, Boggin T, Crowell KE, Allegri F, et al. A study of personal digital assistants to enhance undergraduate clinical nursing education. Journal of Nursing Education. 2005; 44(1): 19-26. PMid:15673170

[22] National Association of College Stores. Electronic book and e-Reader device report. Oberlin, OH:Author, 2010.

[23] On Campus Research - National Association of College Stores. (2010). Student Watch.Students attitudes and perceptions: A comprehensive analysis on textbooks and course materials. Oberlin, OH: Author, 2010.

[24] Student Public Interest Research Groups. High tech textbooks: A snapshot of student opinions [Internet]. 2009. Available from: http://studentpirgs.org/sites/student/files/resources/high-tech-textbooks.pdf

[25] Young J. This could be the year of the E-textbook, The Chronicle of Higher Education. 2009; pp. LVI, A-1, A-12.

[26] Woody WD, Daniel DB, Baker CA. E-books or textbooks: Students prefer textbooks. Computers \& Education. 2012; 55: 945-948. http://dx.doi.org/10.1016/j.compedu.2010.04.005

[27] Williams MG, Dittmer A. Textbooks on tap: using electronic books housed in handheld devices in nursing clinical courses. Nursing Education Perspectives. 2009; 30(4); 220-225. PMid:19753854

[28] Phillippi JC, Wyatt TH. Smartphones in nursing education. Computers, Informatics, Nursing: CIN. 2011; 29(8): 449-454. http://dx.doi.org/10.1097/NCN.0b013e3181fc411f

[29] Healthcare Human Factors. Smartphones for nurses [Internet]. 2009. Available from http://humanfactors.ca/projects/smartphones-for-nurses/

[30] Mosa AS Yoo I, Sheets L. A Systematic Review of Healthcare Applications for Smartphones. BMC Medical Informatics and Decision Making. 2012; 12(1): 67. http://dx.doi.org/10.1186/1472-6947-12-67 
[31] Wittmann-Price RA, Kennedy LD, Godwin C. Use of personal phones by senior nursing students to access health care information during clinical education: staff nurses' and students' perceptions. Journal of Nursing Education. 2012; 51(11): 642-646. http://dx.doi.org/10.3928/01484834-20120914-04

[32] Schulz R, Beach SR, Matthews JT, Courtney KL, DeVito Dabbs AJ. Designing and evaluating quality of life technologies: An interdisciplinary approach. Proceedings of the IEEE. 2012; 100(8): 2397-2409. http://dx.doi.org/10.1109/JPROC.2012.2200558

[33] De Vito Dabbs AJ, Myers BA, Mc Curry KR, Dunbar-Jacob J, Hawkins RP, Begey A, Dew MA. User-centered design and interactive health technologies for patients. Computers, Informatics, Nursing:CIN. 2009; 27(3): 175-183. http://dx.doi.org/10.1097/NCN.0b013e31819f7c7c

[34] Courtney KL, Demiris G, Rantz M, Skubic M. Needing smart home technologies: the perspectives of older adults in continuing care retirement communities. Informatics in Primary Care. 2008; 16(3): 195-201. PMid:19094406

[35] DeVito Dabbs AJ, Beach SR, Courtney KL, Matthews JT. Evaluating Quality of Life Technologies. In Quality of Life Technology Handbook. R. Schulz, ed. Pittsburgh, PA: CRC Press, 2012.

[36] Collins F. How to fulfill the true promise of "mHealth": Mobile devices have the potential to become powerful medical tools. Scientific American. 2012; 307(1): 16. PMid:22779258 http://dx.doi.org/10.1038/scientificamerican0712-16

[37] Bell AM, Fonda SJ, Walker MS, Schmidt V, Vigersky RA. Mobile phone-based video messages for diabetes self-care support. Journal of Diabetes Science and Technology. 2012; 6(2): 310-319.

[38] Jelin E, Granum V, Eide H. Experiences of a web-based nursing intervention--interviews with women with chronic musculoskeletal pain. Pain Management Nursing. 2012; 13(1): 2-10. http://dx.doi.org/10.1016/j.pmn.2011.08.008

[39] Resnick HE, Ilagan PR, Kaylor MB, Mehling D, Alwan M. TEAhM-Technologies for Enhancing Access to Health Management: a pilot study of community-based telehealth. Telemedicine Journal and e-Health. 2012; 18(3): 166-174. http://dx.doi.org/10.1089/tmj.2011.0122

[40] Dowdell EB, Burgess AW, Flores JR. Original research: online social networking patterns among adolescents, young adults, and sexual offenders. American Journal of Nursing. 2011; 111(7): 28-36; quiz 37-28. http://dx.doi.org/10.1097/01.NAJ.0000399310.83160.73

[41] Dunphy H, Finlay JL, Lemaire J, Macnairn I, Wallace JE. 2011. Hands-free communication technology: a benefit for nursing? Journal of Nursing Administration. 2011; 41(9): 365-368. http://dx.doi.org/10.1097/NNA.0b013e31822a7301

[42] Kidd R. Benefits of mobile working for community nurse prescribers. Nursing Standard. 2011; 25(42): 56-60. PMid:21826873

[43] Lyles CR, Harris LT, Le T, Flowers J, Tufano J, Britt D, J, Hirsch IB, Goldberg HI, Ralston JD. Qualitative evaluation of a mobile phone and web-based collaborative care intervention for patients with type 2 diabetes. Diabetes Technology \& Therapeutics. 2011; 13(5): 563-569. http://dx.doi.org/10.1089/dia.2010.0200

[44] DeVito Dabbs AJ, Song MK, Hawkins R, Aubrecht J, Kovach K, Terhorst L, Connolly M, et al. An intervention fidelity framework for technology-based behavioral interventions. Nursing Research. 2011; 60(5): 340-347. http://dx.doi.org/10.1097/NNR.0b013e31822cc87d

[45] Burke LE, Styn MA, Sereika SM, Conroy MB, Ye, L, Glanz K, Sevick MA, Ewing LJ. Using mHealth technology to enhance selfmonitoring for weight loss: a randomized trial. American Journal of Preventive Medicine. 2012; 43(1): 20-26. http://dx.doi.org/10.1016/j.amepre.2012.03.016

[46] Shiffman S, Stone AA, Hufford MR. Ecological momentary assessment. Annual Review of Clinical Psychology. $2008 ; 4$ : 1-32. PMid:18509902 http://dx.doi.org/10.1146/annurev.clinpsy.3.022806.091415

[47] DeVito Dabbs AJ, Dew MA, Myers B, Begey A, Hawkins R, Ren D, Dunbar-Jacob J, Oconnell E, McCurry KR. 2009. Evaluation of a hand-held, computer-based intervention to promote early self-care behaviors after lung transplant. Clinical Transplantation. 2009; 23(4): 537-545. PMid:19473201 http://dx.doi.org/10.1111/j.1399-0012.2009.00992.x

[48] Nilsen W, Kumar S, Shar A, Varoquiers C, Wiley T, Riley WT, Pavel M, Atienza AA. Advancing the science of mHealth. Journal of Health Communication. 2012; 17 Suppl 1: 5-10. http://dx.doi.org/10.1080/10810730.2012.677394

[49] Abroms LC, Padmanabhan N, Thaweethai L, Phillips T. iPhone apps for smoking cessation: a content analysis. American Journal of Preventive Medicine. 2011; 40(3): 279-285. http://dx.doi.org/10.1016/j.amepre.2010.10.032

[50] Melnyk BM. The role of technology in enhancing evidence-based practice, education, heathcare quality, and patient outcomes: a call for randomized controlled trials and comparative effectiveness research. Worldviews on Evidence-Based Nursing. 2012; 9(2): 63-65. http://dx.doi.org/10.1111/j.1741-6787.2012.00245.x 